\title{
e-Phaïstos
}

e-Phaïstos

Revue d'histoire des techniques / Journal of the history

of technology

II-1 | 2013

Savoirs et sciences sur les machines

\section{Discussions on the History of Technology of Traditional Chinese Alcohol Brewing}

A propos de l'histoire des techniques de brassage de l'alcool en Chine

\section{Jian Feng and Guo Li}

\section{OpenEdition}

\section{Journals}

Electronic version

URL: http://journals.openedition.org/ephaistos/5565

DOI: 10.4000/ephaistos.5565

ISSN: 2552-0741

\section{Publisher}

IHMC - Institut d'histoire moderne et contemporaine (UMR 8066)

\section{Printed version}

Date of publication: 1 June 2013

Number of pages: $87-93$

ISSN: $2262-7340$

\section{Electronic reference}

Jian Feng and Guo Li, «Discussions on the History of Technology of Traditional Chinese Alcohol Brewing ", e-Phaïstos [Online], II-1 | 2013, Online since 15 December 2019, connection on 18 June 2020. URL : http://journals.openedition.org/ephaistos/5565 ; DOI : https://doi.org/10.4000/ephaistos. 5565 


\title{
Discussions on the History of technologie of Tradition- al Chinese Alcohol Brewing
}

\author{
Jian Feng \\ General Director of Department of \\ Cultural Relic, Luzhou, China ${ }^{i}$ \\ Guo Li \\ Researcher, architect ${ }^{\mathrm{ii}}$
}

\begin{abstract}
China is one of the earliest countries in the world of vintage and its technology has distinctive features, and rich connotations with the society. Evidence shows that Chinese alcohol has nearly five thousand years of history 3 . In this article, Chinese distilled alcohol is referred to as Baijju, its special appellation, which is catalyzed by $Q u$ (saccharification and fermentation agent), using cereals, by cooking, saccharification and fermentation, distillation, storage and blending. Along with brandy, whisky, vodka, rum and gin, Baijiu is among the world's six distilled alcohols. As a traditional biological fermentation engineering, Baijiu is a typical representative of Chinese science and technology, especially for its economic, social and technical interactions.

Chinese alcohol brewing technology is different from Western malt beer or wine brewing processes, as many countries in the world mostly use sprout saccharification technology, liquid fermentation and aging in a special container. In China, traditional alcohol is brewed using $Q u$, a natural microbial inoculation. The grain, especially sorghum, and $Q u$ undergo solid-state fermentation in the special cellar known as Jiao; and then, distilled to produce the rich aromatic, mellow, soft, long aftertaste alcohol. As it is transparent, it is also called "white alcohol" in Chinese. Compared to Western alcohols the originality of this "white alcohol" lies in the starter, $Q u$ and the cellar, Jiao..
\end{abstract}

First of all, white alcohol is the high-end product of the development of traditional Chinese brewing technology and it goes through three important stages: 1."use of $Q u$ and Nie at the same time"; 2. "use of $Q u$ alone"; 3. "from $Q u$ to fermentation and distillation".

The first stage dates no later than the Warring States Period (475 BC - 221 BC), as the Chinese already had sayings like, "Yi Di makes alcohol, $Y u$ drink."4 ; "if you make alcohol, you must use Nie."5 ; "the cereals must be added in order; $Q u$ must be added in time."6

The second stage, also known as the formation of Chinese brewing system dates back to the Northern Song Dynasty (960 1127). According to statistics, more than 10 species of yeast were found just in the middle and lower regions of the Yellow River. Based on their fermenting power, they were divided into "clever yeast", and "stupid yeast"7 .Red yeast was also found in the Song Dynasty ${ }^{8}$, and Nie was separated from $Q u$, to be used in other fermentable foods whereas $Q u$ was used only in alcohol. Yeast technology gradually fractionized and a strong alcohol called "can't drink more than three liters"9 was invented. And during the Han dynasty (202 BC220) many monographs and writings on wine emerged: "Shang Jiu Tan Fa Zhou » by Cao Cao of Eastern Han Dynasty, "Qi Min Yao Shu » by Gu Sixie of the Northern Wei Dynasty, and in the Northern Song Dynasty, «Bei Shan Jiu Jin » by 
Zhu Hong, Dou Pin's «Jiu Pu», Li Bao's «Xu Bei Shan Jiu Jing», and Su Shi's «Jiu Jing» to name a few.

The third stage is marked by the emergence of

Fig.1. Three types of cellar:

Vat cellar

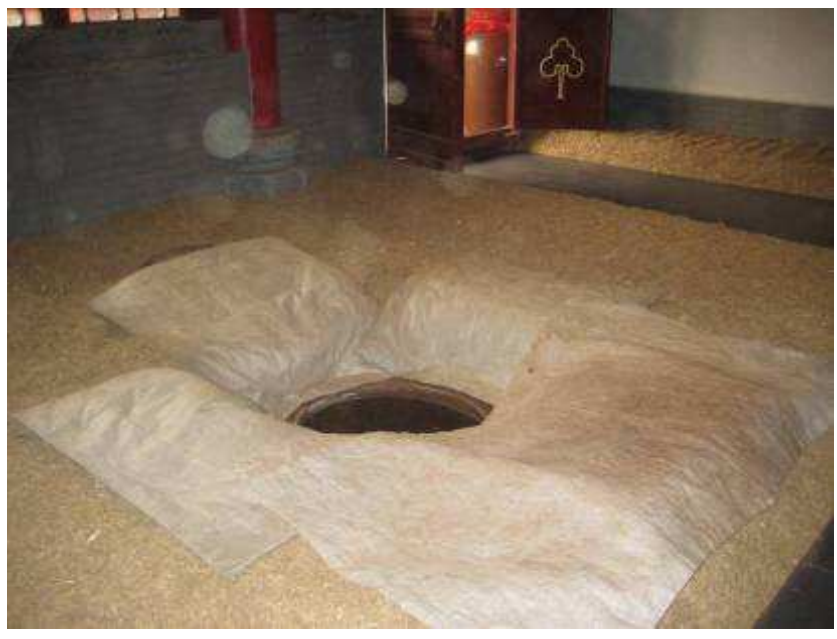

Stone cellar

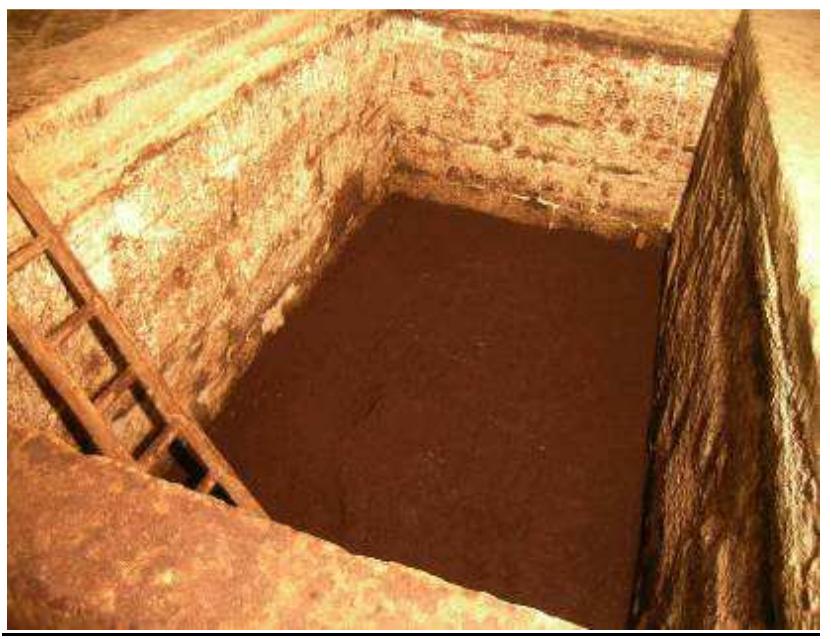


the "distillation" process. There are different opinions regarding its nascent. Evidence found in different parts of China shows the presence of the "distillation" process in the Eastern Han Dynasty, the Tang Dynasty, the Song Dynasty (including the Jin Dynasty) and the Yuan Dynasty. Based on literary and archaeological evidences, it is more convincing that traditional Chinese alcohol brewing technology started since the Yuan Dynasty. This however does not exclude that in some areas of China, a small number of non-social brewery distillation activities existed before the Yuan Dynasty ${ }^{10}$. Due to the distillation process involved in wine-making, traditional Chinese alcohol brewing technology entered a new era, and since then, it has come to the world stage of distilled alcohols.

Fig.2 : Alcohol Distillation Griller : Model Profiles in Guizhou Province, Southwest China

Miao Shan village
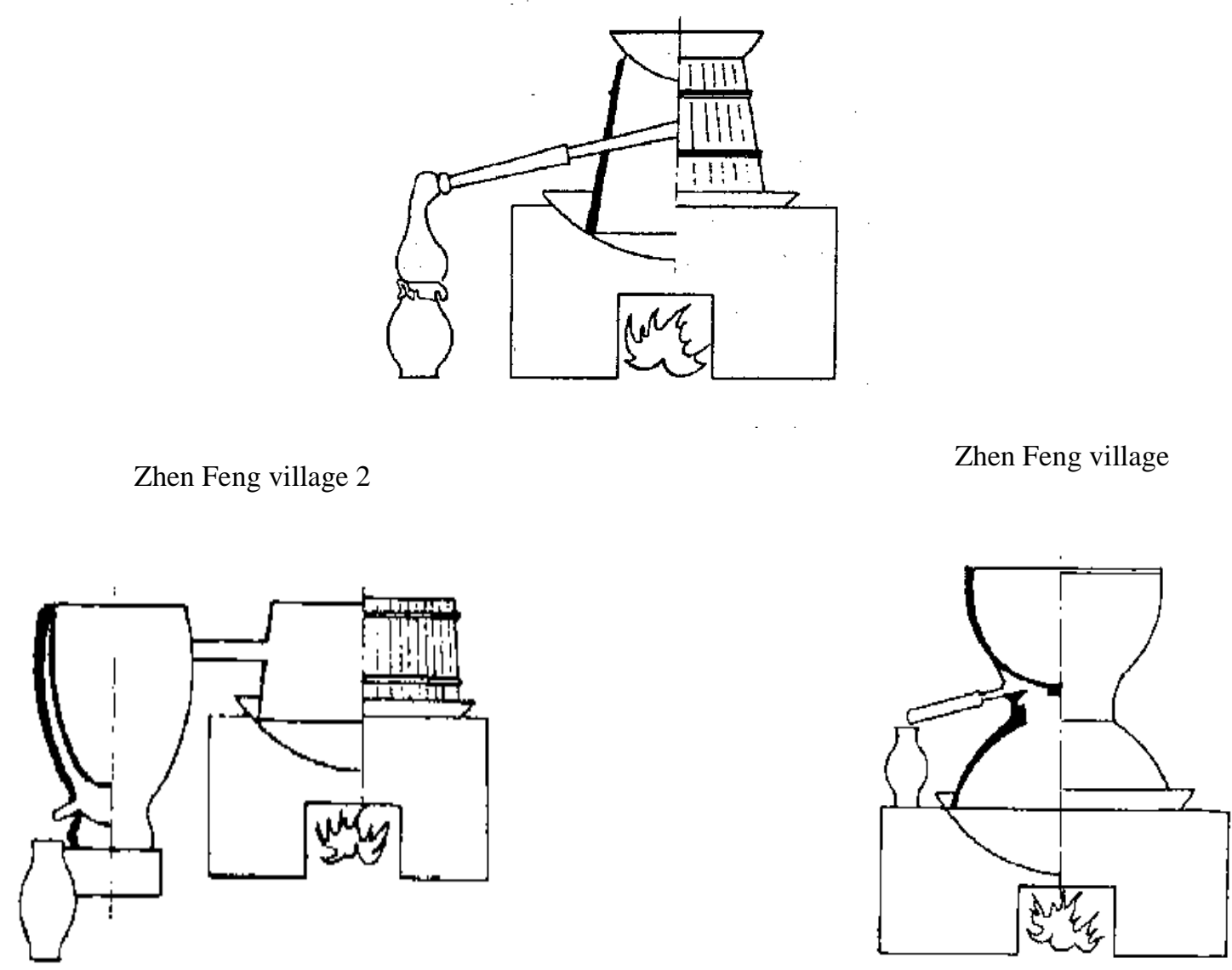
Secondly, the Chinese traditional alcohol fermentation and distillation process is unique. The alcohol workshop, also known as the "burning square", consists of many types of traditional brewing equipments: the most important one being the cellar. In recent years, in the site of Shuijingjie Workshop (Sichuan province) and Lidu workshop (Jiangxi province), archaeological finds show that in the Yuan and Ming Dynasties, traditional alcohol factory had the Liangtang (a terrace to dry the ingredients, spices and distilled grains), a cellar (for the fermentation of lees), stove (for distillation of grains), wells and some other production facilities ${ }^{11}$. The cellar inside the alcohol workshop is the fermentation container created by different brewing skills in China combined with their local environment. According to the shapes, there are three big categories of cellars (fig.1): the mud cellar, the vat cellar and the stone cellar. Usually located on the floor of the workshop, these cellars are the habitat of microbe proliferation and require perennial manual maintenance. It is the combination of different microbes that gives the alcohol its special flavor. For example, the Site of Cellar Cluster for Luzhou Laojiao Daqu Liquor (Chinese national heritage) is a mud cellar that has been used for more than 400 years.

Another important traditional equipment in the workshop is the distillery which has experienced a long process from the early distillation and cooling system to separation. From the shape of the distillation griller equipment used today in the Guizhou Province of southwest China, the Ming and Qing dynasties are the most important periods of development when distillation and cooling became two separate processes (fig.2).

Thirdly, traditional Chinese brewing workshop's production layout contains a rich tradition of commercial, industrial and agricultural characteristics. According to research, Chinese alcohol production layout was finalized by the end of the Qing dynas- ty ${ }^{12}$. If we take the largest province of alcohol production - Sichuan - for example, the alcohol production layout in this province is closely related to its water and land transportation systems, trade networks, raw materials planting base as well as urbanization. Chengdu, as the center of the province, was connected far and near by the official road since ancient times thereby making it the center of alcohol production and trade ${ }^{13}$. The waterways developed along the rivers of Jinsha, Yongning, Chishui, Qi and Wu. Many alcohol workshops were located in the river towns along the upper reaches of the Yangtze River: Yibin, Luzhou, Jiangjin, Chongqing and Fengdu on the Yangtze River have become the most important alcohol sales areas ${ }^{14}$. Some small-scale workshops were often adjacent to traffic arteries and commercial centers. That's why nowadays in the southwest of China, the layout of alcohol production sites are mostly next to the land routes and rivers.

The Chinese alcohol brewing technology has rich cultural characteristics. Its cultural values, authenticity, integrity and endangered factors must be cherished in the context of today's globalization.

Firstly, Chinese alcohol brewing technology presents a unique process and the pioneering spirit of the Chinese people, which is a combination of Chinese philosophy and technology. Though it belongs to traditional bio-engineering techniques, phrases such as "yin and yang in the alcohol are deep hidden" or "the movements of yin and yang should be used well"15, can be seen used as part of the technical vocabulary. This clearly shows the world-view of ancient Chinese: "yin and yang are harmonious," "environment and people are harmonious". Furthermore, the technology of yeast-making was being perfected without having the capacity to explore the microscopic world. This technology has been extended to vinegar, soy sauce and some other industries, and widely disseminated in the entire East Asian region ${ }^{16}$.

Secondly, its unique brewing equipment has a 
significant place in the world. In accordance with the habits of Chinese alcohol sector, cellars more than 30 years old - locally known as "old cellars"can be found in abundance in various parts of China ${ }^{17}$ and are considered to be the wealth of major alcohol companies. It must be pointed out that Chinese rice alcohol, wine, beer, medicinal alcohol, etc. are fermented without a cellar, which is used only for white alcohol. As mentioned earlier, there are mud cellars, vat cellars and stone cellars. The mud cellar is the most utilized due to its wide distribution and quantity, and the main products of Chinese white alcohol come from inside of these cellars. This type of cellar has many common characteristics, in particular, the longer the life of the cellar, the richer the microbe inside, and the better the quality of the alcohol. The proverb "millennium old cellar, ten millennium old yeast" summarizes the traditional characteristics of Chinese white alcohol, and highlights the key role of cellar fermentation in alcohol production.

Thirdly, the production layout is a unique pre-industrial urban landscape. In the preindustrial era, most traditional alcohol production areas followed the "front shop - back factory - next to the road or river" mode of production. Many cities are therefore known as the "city of alcohol", "town of alcohol" or even "country of alcohol". In particular, a number of old workshops are still in situ layout of the old city. During the production season, the city is filled with the aroma of alcohol, which has become a special feature of the current urban landscape. On the other hand, as functional industrial sites, some of them have been listed as cultural heritage by the local governments, which are influencing the planning and urban design. For example, in the city of Luzhou, there are 10086 cellars in the old city, and 1 619 of them with more than one hundred years of history are listed as cultural heritage of the Sichuan province, while four have entered the country's national heritage list ${ }^{18}$. From the map (fig.3), we can see that the urban tissue of the city of Luzhou is well preserved because of these alcohol factories, giving it the title of "the city of alcohol in China".

Fourthly, the white alcohol is an important catalyst for arts, culture, folk customs and economic development in China. The traditional Chinese

Fig.3.Alcohol factories in the old city of Luzhou

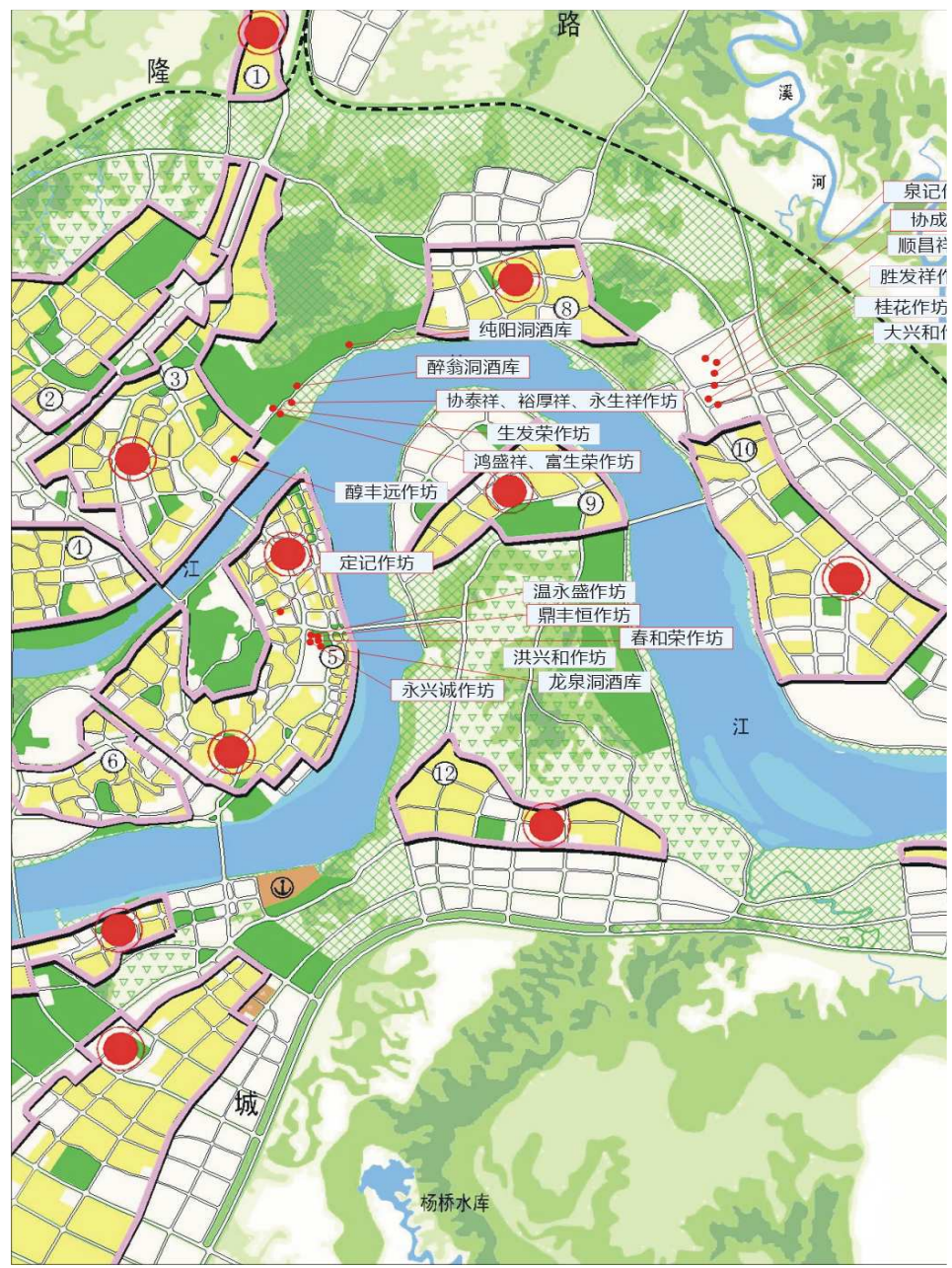


brewing technology having developed on the basis of yellow rice alcohol (fermented juice of rice), inherits and develops yellow rice alcohol while creating a variety of characteristics according to the local conditions and matches the technology of yeast fermentation process. Since its entrance into the daily lives of people, it has established a deep bond with the local culture, becoming a source of inspiration and intercultural exchange, playing a wonderful role in the creation of poetry, drama, dance, calligraphy, etc. ${ }^{19}$. On certain occasions, like receiving friends, celebrations or feasts, the alcohol plays an important role in the coalescing of groups. There are even sayings like "no alcohol no ceremony, no alcohol no joy, no alcohol no honor", "seat is always full of guests, cup is always full of alcohol". As a result, alcohol has become far beyond just a beverage with regards to social development. Many folk customs associated with it have upgraded to etiquettes. Also, alcohol tax has always been and is very essential to the national financial income.

Fifthly, traditional Chinese alcohol brewing technology is challenged with the pressure and risk of disappearance. With China's current society, economy, and culture drastically changing, especially under the influence of global economic integration, this traditional technology is dying. For example, in order to reduce labor intensity, a large number of alcohol companies have mechanized the mode of production and replaced traditional means of production, thereby causing a survival crisis for traditional skills pertaining to the manual labor process. Also, the natural changes in the environment and the traditional mentoring inheritance chain fracture have also caused the demise or distortion of this Chinese handicraft.

Traditional Chinese alcohol brewing technology has distinctive features of national character. Many of its tangible and intangible factors are important technical heritage of the Chinese agricultural civilization. It is a part of the history of Chinese civilization, which should be scientific and rational, con- served and utilized. However, in the current Chinese modernization process, the display and use of this traditional technology is confronted with many problems. How to protect? How to use? From which example can we learn? How to develop a region with the help of this heritage? These are some of the questions that have been placed in front of the government, traditional alcohol companies and academia for decades. Based on the international industrial heritage protection and management standards applied to cases like the Agave landscape and ancient industrial facilities of tequila ${ }^{20}$, we propose the following for the protection and management of traditional Chinese alcohol brewing technology and its carriers.

First of all, we look at the protection of this traditional technology dating back to agricultural civilizations within the context of global industrial heritage protection; it has its own special characteristics as well as difficulties. As emphasized in the "Nizhny Tagil Charter" 21 we should "also examine its earlier pre-industrial and proto-industrial roots". We should consider and respect this diversity, and protect this special industrial heritage which draws on the study of work and working techniques encompassed by the history of technology"

Secondly, research should be conducted on the standards and management of Chinese alcohol industrial heritage. According to statistics, there are 20 types of alcohol making processes, sites, workshops and intangible cultural heritage that have been classified as Chinese national cultural heritage. Seven among these are national protected sites, and some of them have even entered UNESCO's tentative list of world heritage sites $^{22}$. These heritages not only reflect the cultural diversity of China's traditional alcohol, indicating the characteristics of Chinese brewing technology, its originality and uniqueness but also show China's outstanding contributions to the progress of human civilization. Therefore, keeping in mind these characteristics, Chinese cultural heritage management agencies should actively carry out research on alcohol indus- 
try heritage standards, provide a guideline and define strategies for protection and management of Chinese alcohol industrial heritage.

Also, based on the national and provincial list of alcohol industrial heritage, proper conservation and management plans need to be instituted. It should take into consideration the existing environment and territory as well as the redevelopment of the area (both urban and rural).

i Contact Author: Jian, Feng, General Director of Department of Cultural Relic, Luzhou, China - Postal address: Jiangyangxi Road 35, 646000 Luzhou, China - Tel: oo86 o830 3156221 Fax: 0086 08303118400 - e-mail: fengjian72@foxmail.com.

ii Contact Author : Guo, Li, architect, - Postal address: K Vystavisku 529/3, 91101 Trencin, Slovak Republic - Tel: 00421944349675 Email: liguo923@hotmail.com.

${ }^{3}$ Hong Guangzhu, Technological Development History of Chinese Alcohol (China Light Industry Press, 2001).

${ }^{4}$ Liu Xiang, Intrigues of the Warring States, (China, Han Dynasty).

${ }^{5}$ Shang Shu - Shangs Shu - Shu Min

${ }^{6}$ Yang Tianyu, Li JI-Yi Zhu, (Shanghai, Shanghai ancient books, 2004)

${ }^{7}$ Jia Siqi, Qi Min Yao Shu - Ben Qu Bin Jiu 66, 10 (Northern Wei Dynasty)

${ }^{8}$ Wei Gu, Qing Yi Lu ( Northern Song Dynasty)

${ }^{9}$ Jia Siqi, Qi Min Yao Shu - Ben Qu Bin Jiu 66, 10 (Northern Wei Dynasty)

${ }^{10}$ Zhou Jiahua, "Analysis of the Historical Data from Chinese Distilled Alcohol Source", History of Natural Science14, no.3 (1995): 227-238.

${ }^{11}$ Ancient alcohol workshops have a special internal layout. According to the Southern Song Dynasty, Zhou Yinghe said (Jing Ding Jian Kang Zhi), "The door and hall of an alcohol workhop should face the North. Behind the hall is the rest room for the workers; in front of the door, is the room of the boss and God. Entrepot is to the left, the factory and stove are to the right. Cellar and well are obligatory and have to be in the right place..."
${ }^{12}$ Wang Yancai, Chinese Alcohol, (China Light Industry Press, 2011)

13 http://www.phoer.net/history/minguo/alcohol.htm, consulted in April 2012

${ }^{14}$ Sichuan Folk Research Association, Sichuan alcohol Culture and Social Economy Research (Chengdu, Sichuan University, 2000)

${ }^{15}$ Peng Renzhong, Alcohol Industry Research (Beijing, Beijing University Presse, 1998)

${ }^{16}$ Joseph Needham, Science and Civilisation in China, Vol 6 Part 5 (Science Press, 2008)

${ }^{17}$ Peng Renzhong, Alcohol Industry Research (Beijing, Beijing University Press, 1998)

18 Yang Xin, Cultural Heritage of Luzhou Laojiao (Luzhou Press, 2011)

${ }^{19}$ Li Zhenpin, Chinese alcohol culture (Current Affairs Press, 2007)

${ }^{20} \mathrm{http}: / /$ whc.unesco.org/en/list/1209, consulted in May 2012

21 http://international.icomos.org/18thapril/2006/nizhny-tagil-chartere.pdf, consulted in May 2012

${ }^{22}$ http://whc.unesco.org/en/tentativelists/5320/, consulted in May 2012 